\title{
Examining Relationships between Food Procurement Characteristics and Nutritional Quality in Washington State Child Care Settings
}

\author{
Monica A. Lazarus, MPH, Pooja S. Tandon, MD, MPH, and Jennifer J. Otten, PhD, RD'
}

\section{Abstract}

Background: Sixty percent of US children 5 years old and under receive up to two-thirds of their daily nutrition in early care and education (ECE) settings. Although participation in the federal Child and Adult Care Food Program (CACFP) is shown to improve nutrition, little is known about the relationship between procurement practices (where and how child care programs purchase food) and nutrition in ECE settings or whether these practices differ depending on participation in CACFP.

Methods: We assessed self-reported nutrition practices and procurement practices by CACFP participation using a 2013 crosssectional survey of 690 Washington ECE centers ("Centers") and 1260 family homes (family home child care [FHCCs]) serving children aged 2-5 years old using validated survey tools. We examined the relationship between procurement variables (i.e., main store and main mode) and nutrition scores using multinomial logistic regression models that adjusted for sociodemographic and program characteristics.

Results: In-person shopping was the primary mode of shopping for all programs, regardless of CACFP participation. Some Centers but very few FHCCs reported online shopping as their primary mode. Centers and non-CACFP FHCCs shopped primarily at megastores (Costco, Target, etc.). CACFP FHCCs used both megastores and grocery stores (Albertsons, QFC, etc.) at similar rates. Adjusted multinomial models found that shopping online or at two or more stores was associated with higher nutritional quality of foods served by programs.

Conclusions: Understanding the procurement behaviors of ECE programs helps to illuminate and prioritize potential interventions that would support healthy food purchases.

Keywords: child care; food procurement; food purchasing; nutritional quality; procurement policies

\section{Background}

$\mathbf{S}$ ixty percent of children $<5$ years of age in the United States are enrolled in one form of early care and education (ECE) or another at least once weekly, and receive up to two-thirds of their daily nutrition in these settings. ${ }^{1}$ Early childhood is an important time for establishing healthy eating preferences and standards., ${ }^{2,3}$ Previous research in young children has illustrated that taste preferences are largely developed and that openness to novel foods is at its peak in this age group. ${ }^{2,3}$ Prior studies have also found a positive linear relationship between time spent in ECE settings and child risk for overweight and obesity. ${ }^{4,5}$ Thus, given the extent to which ECE programs are utilized in the United States, they are an important setting for establishing healthy eating preferences and habits. ${ }^{2,3,6-9}$

Research has illustrated that nutrition practices in these settings are determined by a variety of factors, such as individual-level factors (i.e., perceptions, values, and nutrition knowledge of staff), interpersonal factors (i.e., children' and parents' food preferences and mealtime practices), institutional characteristics (i.e., budgets, kitchen space, and institutional policies), community-level factors (i.e., food environment/availability), and societal factors (i.e., culture, nutrition policies, and licensing requirements). ${ }^{9-11}$ Within the context of child care, most of the extant research literature focuses on the association between

\footnotetext{
'University of Washington School of Public Health, Nutritional Sciences Program, Center for Public Health Nutrition, Seattle, Seattle, WA. ${ }^{2}$ Seattle Children's Research Institute, Center for Child Health, Behavior, and Development, University of Washington General Pediatrics, School of Medicine, Seattle, Seattle, WA.
} 
Child and Adult Care Food Program (CACFP) and nutrition. ${ }^{12-15} \mathrm{CACFP}$ is a federal program that is administered by each state, often with additional requirements, which aims to improve the nutritional quality of meals served to children in ECE settings. ${ }^{13,16}$ Prior research finds CACFP participation to be associated with better nutrition outcomes. ${ }^{12-14}$

To date, no studies have investigated the relationship between procurement practices and nutrition outcomes within the context of ECE settings. Food procurement refers to where (i.e., source) and how (i.e., mode) child care sites purchase food. ${ }^{17}$ Good procurement strategies can support healthy food purchasing and service practices. ${ }^{17,18}$ Outside the context of child care, research shows how procurement characteristics impact food choices, dietary quality, consumption, and nutritional outcomes. ${ }^{19,20}$ Aggarwal et al. found that fruit and vegetable consumption was not related to the physical distance of supermarkets, but instead supermarket choice. ${ }^{21}$ Another study found that urban supermarkets, which typically carry more nutritious foods, were associated with lower obesity rates, whereas convenience stores were associated with higher obesity rates. ${ }^{22}$

Although most studies examine how factors impact food procurement choices at an individual level, there are few studies on how child care programs approach procurement. $^{23-25}$ A recent qualitative study of ECE programs underlined the complexities of food purchasing behavior in that programs have to balance their own institutional standards and enrollee preferences with national and statelevel policies and limited budgets and resources. ${ }^{11,26}$ Otten et al. indicated that food source was an essential component related to the quality, price, and trustworthiness of food and that purchasing mode was related to time management. ${ }^{11,26}$ However, the study only interviewed 16 ECE providers and did not provide information about where and how most child care providers shopped for food.

In 2013, the University of Washington Center for Public Health Nutrition administered a statewide census survey to understand the state of nutrition and physical activity practices in licensed Washington State child care programs serving $\sim 150,000$ children aged $2-5$ years old. The purpose of this secondary analysis was to characterize child care food procurement practices by licensed ECE centers ("Centers") and family homes (FHCCs) and CACFP participation and to explore relationships between child care procurement practices and the nutrition practices. These findings can be helpful for identifying whether and how food procurement practices could be used as an intervention point to optimize the balance between most affordable and healthiest foods.

\section{Methods}

\section{Overview}

The complete methodology of the 2013 Washington Child Care Survey and select results are published elsewhere. ${ }^{27,28}$ We used the 2013 survey results to initiate a secondary and exploratory analysis. Briefly described be- low are survey tool development, administration, and measures relevant to this analysis.

\section{Survey Tool Development}

Survey design was informed by an advisory group and a literature review of current nutrition and physical activity research and standards that promote healthy child development. ${ }^{29-32}$ Validated assessment tools were incorporated into the survey or were used to design robust survey questions, including the Nutrition and Physical Activity Self-Assessment for Child Care, Rudd Center's Child Care Nutrition and Physical Activity Assessment Survey, Oregon Public Health Institute's Right from the Start, and UC Berkeley's CA Survey of Child Care Providers of 2-5Year Old Children. ${ }^{33-36}$

The 2013 statewide survey included a total of 153 questions from 12 topic areas: (1) program characteristics, (2) respondent characteristics, (3) foods and beverages provided, (4) meal and snack time environment, (5) procurement characteristics, (6) time for physical activity, (7) physical activity environment, (8) screen time, (9) challenge attitudes and beliefs, (10) provider training, (11) program policies, and (12) communication with families. ${ }^{27,28}$ Our secondary analysis focuses on 48 of these questions from the following topic areas relevant to our study aims: (1) program characteristics, (2) respondent characteristics, (3) foods and beverages provided, (4) meal and snack time environment, and (5) procurement characteristics. Each of these is described in the sections below on Respondent Characteristics, Child Care Programs Characteristics, Procurement Characteristics, and Nutrition Best Practices.

\section{Survey Administration}

The Washington Department of Early Learning provided a complete list of all licensed programs, which served as the sampling frame. The survey was administered from October to December 2013 using Dillman's Tailored Design Method for Internet and mail surveys. ${ }^{37}$ ECE sites with valid e-mail addresses received the online survey, and sites without email addresses were mailed paper surveys. The University of Washington Institutional Research Board determined that the study survey procedures and analysis were exempt.

\section{Respondent Characteristics}

The survey collected participants' race/ethnicity, education, and number of years employed in ECE. For the analysis, race and ethnicity were combined into four categories: non-Hispanic whites, non-Hispanic blacks, Hispanics, and other race. Education was coded into four categories: less than high school (HS), HS graduate, some college, and greater than an associate degree. Number of years employed categories were $0-5,6-10,11-20$, and $>20$ years.

\section{Child Care Programs Characteristics}

The survey asked respondents about the type of child care (Centers vs. FHCCs), CACFP status (enrolled or not enrolled), 
program length (half-day, full-day, or both), and Head Start and Early Achievers (Washington's Quality Rating and Improvement System for ECE facilities) participation.

\section{Procurement Characteristics}

Survey respondents were asked about their main mode of shopping (in-person, online, and over the phone) and their main shopping store. For the main mode of shopping, respondents were asked how they primarily obtained the program's food. For the main shopping store question, respondents could select from an extensive list of grocery stores, markets, and shops; food service distributors; and caterers; or write-in an option. Answers to main shopping store were recoded into six categories: no main store, megastores (e.g., Costco and Sam's Wholesale Club), food service distributors, other stores, grocery stores, and more than two stores.

\section{Nutrition Best Practices}

Respondents were asked how many times they served different types of specific foods and beverages to children ages 2-5 years old, and what their meal and snack time environments were like. For example, "How often does your Center offer fruit canned in syrup (heavy or lite syrup)," "What type of milk is offered to children of ages 2 years and older," and "Are children allowed to decide how much or how little food they will eat?" These questions were categorized into five content areas [(i.e., fruits and vegetables $(n=5)$, whole grains, snack foods, and sweets $(n=5)$, fried foods and processed meat $(n=3)$, beverages $(n=4)$, and supporting healthy eating $(n=5)]$. Each content area had four to five response choices scored on a scale of $1-5$, with 5 corresponding to a national best-practice child care standard, and hence the highest score attainable.

Some of the responses to the nutrition questions were reverse coded, to reflect nutrition best practices. Scores for each content area were then averaged and summarized into a composite nutrition score, as shown in Figure 1. We then categorized our composite nutrition scores into tertiles-high, medium, and low composite nutrition score categories.

\section{Statistical Analysis}

To compare Centers and FHCCs, chi-square tests were used to test for difference in response distributions for categorical responses and two-sample $t$-tests were used to test for mean differences in the continuous responses. Linear regressions were used to examine the bivariate associations of composite nutrition scores with key sociodemographic, program, and procurement characteristics. A series of multinomial logistic regression models explored the relationship between each procurement variable (i.e., main store and main mode) and the composite nutrition score tertile categories. The reference groups in all the models were the groups that had the largest proportion of responses.

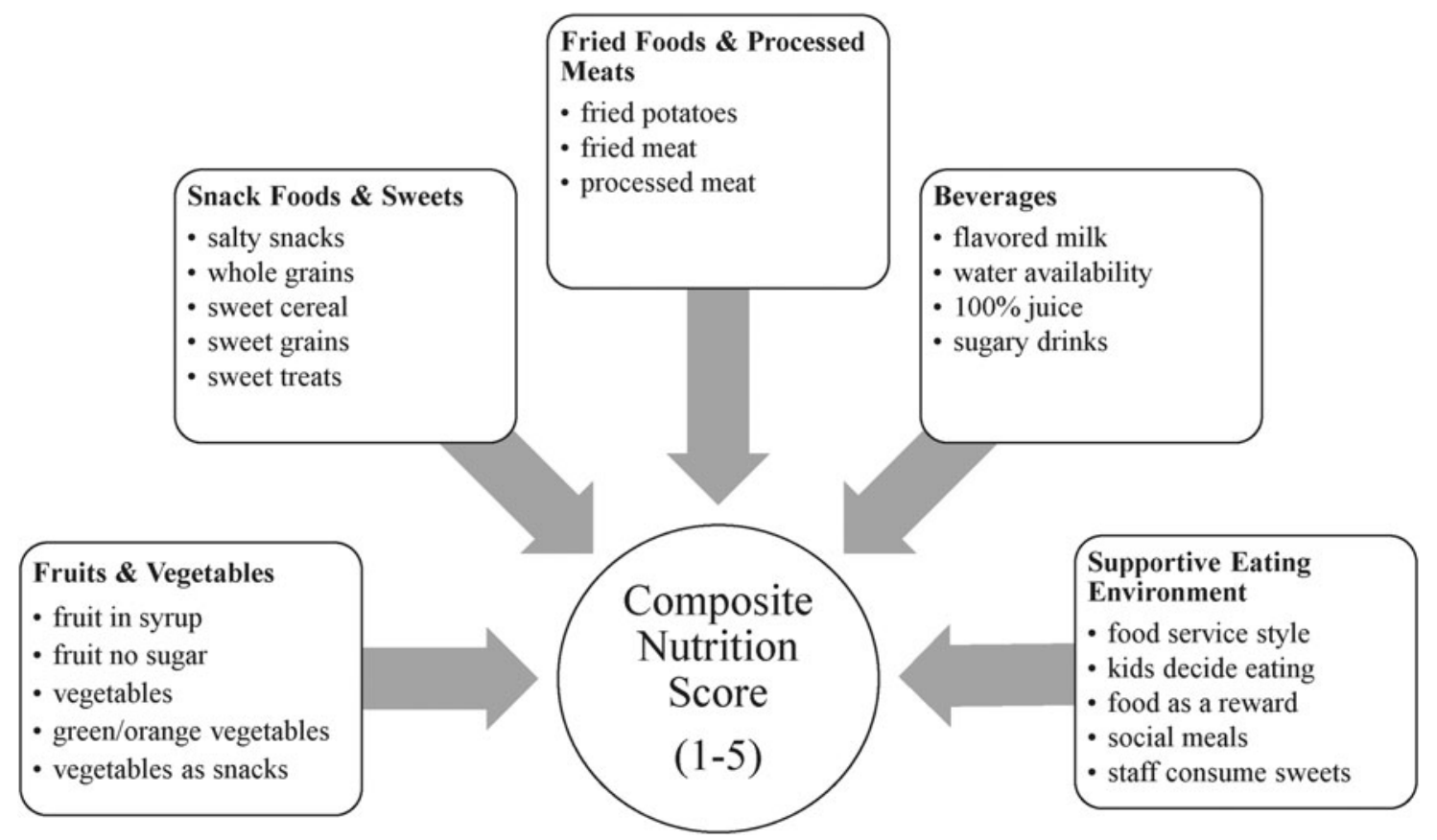

Figure 1. Composite nutrition score tabulation from five distinct content areas. Composite nutrition score questions were categorized into five content areas [i.e., fruits and vegetables $(n=5)$, whole grains, snack foods, and sweets $(n=5)$, fried foods and processed meat $(n=3)$, beverages $(n=4)$, and supporting healthy eating $(n=5)]$. All questions had four to five response choices scored on a scale of 1 to 5 , with 5 corresponding to a national best-practice child care standard, and hence the highest score attainable. Some of the responses to the nutrition questions were reverse coded to reflect nutrition best practices. The scores for each content area were then summed and averaged, resulting in a single composite nutrition score for each child care program. 


\section{Results}

Out of 5540 programs invited, $36 \%$ or 1973 WA Centers and FHCCs took the survey (Center and FHCC response rates were $46 \%$ and $32 \%$, respectively). These analyses were limited to the 1950 programs (690 Centers, 1260 FHCCs) that cared for children aged 2-5 years. Table 1 shows the descriptive characteristics of the survey respondents. Responders for the Centers relative to FHCCs tended to have a higher proportion of whites and had higher education levels.

Table 2 shows the program characteristics. As shown in Table 3, a majority of Centers and all FHCCs prefer an inperson food shopping mode for purchases, regardless of CACFP participation. Some Centers and only three FHCCs reported using online resources as their primary mode. Relatively few Centers and no FHCCs reported using the phone as their primary mode.

Table 4 illustrates where Centers and FHCCs primarily shop. CACFP and non-CACFP Centers and non-CACFP FHCCs primarily shop at megastores, whereas CACFP FHCCs use megastores and grocery stores at similar rates.

Table 5 shows overall composite nutrition scores and nutrition scores by content area. CACFP sites had significantly higher overall composite nutrition scores and beverage scores and performed better in supporting healthy eating as compared with non-CACFP sites $(p<0.001$, $p<0.001, p<0.05$, respectively). Nutrition scores for fruits and vegetables were not significantly different between Centers and FHCCs, regardless of CACFP participation $(p=0.810)$. Non-CACFP Centers and FHCCs had substantially higher nutrition scores for fried foods and processed meats than their CACFP counterparts $(p<0.001)$.

Table 6 reports the bivariate associations between composite nutrition scores and key sociodemographic, program characteristic, and procurement variables. There was a significant association between composite nutrition scores and key sociodemographics (i.e., race/ethnicity, education, and years employed), child care program characteristics (i.e., child care type and CACFP enrollment), and procurement characteristics (i.e., main store for shopping and main mode of shopping). The composite nutrition score was significantly higher for Centers than for FHCCs $(p<0.001)$, for CACFP sites than for non-CACFP sites $(p<0.001)$, and for sites shopping online than for in-person shopping mode $(p<0.001)$.

Table 7 shows the multinomial logistic analyses comparing the high and low composite nutrition score category tertiles (i.e., the dependent variable) with procurement variables (i.e., main store and main mode, and the primary independent variables). In Model 1 (adjusted for race/ ethnicity, education, and years employed), shopping at food service distributors and shopping at two or more main stores compared with megastores were more likely to result in high composite nutrition scores $(p<0.05)$. In Model 2 (adjusted for race/ethnicity, education, years employed, and type of child care) and Model 3 (adjusted for race/ ethnicity, education, years employed, type of child care,

\section{Table I. Demographic Characteristics \\ of the 2013 Washington State Survey \\ of Nutrition and Physical Activity \\ in Child Care Survey Respondents}

\begin{tabular}{|c|c|c|}
\hline Demographic characteristic & $\begin{array}{c}\text { Centers }^{a} \\
(N=690) \\
n(\%)\end{array}$ & $\begin{array}{c}F H C C s^{a} \\
\left(\begin{array}{c}N=1260) \\
n(\%)\end{array}\right.\end{array}$ \\
\hline \multicolumn{3}{|l|}{ Primary role ${ }^{b}$} \\
\hline Center director & $485(70)$ & N/A \\
\hline Center owner & $48(7)$ & $\mathrm{N} / \mathrm{A}$ \\
\hline $\begin{array}{l}\text { Other (assistant, supervisor, } \\
\text { manager, teacher, and volunteer) }\end{array}$ & $17(2)$ & $\mathrm{N} / \mathrm{A}$ \\
\hline Two roles & $84(12)$ & N/A \\
\hline Three or more roles & $56(8)$ & $\mathrm{N} / \mathrm{A}$ \\
\hline $\begin{array}{l}\text { Family home child care } \\
\text { owner/provider }\end{array}$ & N/A & $1216(97)$ \\
\hline $\begin{array}{l}\text { Family home child care } \\
\text { teacher, assistant, or volunteer }\end{array}$ & N/A & $6(0.5)$ \\
\hline Two roles & N/A & $30(2)$ \\
\hline Three or more roles & $\mathrm{N} / \mathrm{A}$ & $5(0.4)$ \\
\hline \multicolumn{3}{|l|}{ Race/ethnicity } \\
\hline Non-Hispanic white & $544(80)$ & $822(66)$ \\
\hline Non-Hispanic black & $21(3)$ & $72(6)$ \\
\hline Hispanic & $67(10)$ & $26 I(2 I)$ \\
\hline Other race & $49(7)$ & $90(7)$ \\
\hline \multicolumn{3}{|l|}{ Highest level of education } \\
\hline Less than HS & $I(0.1)$ & $115(9)$ \\
\hline Completed HS & $10(1)$ & $260(2 I)$ \\
\hline $\begin{array}{l}\text { Some college-level or } \\
\text { advanced courses }\end{array}$ & $|5|(22)$ & $459(37)$ \\
\hline Associate degree and higher & $528(77)$ & $414(33)$ \\
\hline \multicolumn{3}{|l|}{ Years employed in child care (years) } \\
\hline $0-5$ & $82(12)$ & $184(15)$ \\
\hline $6-10$ & $119(17)$ & $227(18)$ \\
\hline $11-20$ & $243(35)$ & 432 (35) \\
\hline $20+$ & $246(36)$ & 406 (33) \\
\hline
\end{tabular}

Only includes programs that reported to care for children of ages 2-5 years.

${ }^{a}$ Column totals do not sum up because missing data (unreadable, no response, and "I don't know" responses) were excluded.

bSeparate questions were asked of Centers and FHCCs.

FHCC, family home child care; HS, high school.

and CACFP participation), shopping at two or more main stores compared with megastores was more likely to result in high composite nutrition scores $(p<0.05)$. All three models showed that online shopping compared with inperson shopping was significantly more likely to result in high composite nutrition scores. 


\begin{tabular}{|c|c|c|c|}
\hline Program characteristic & $\begin{array}{c}\text { Centers }^{\mathrm{a}} \\
(\mathrm{N}=690), n(\%)\end{array}$ & $\begin{array}{c}\text { FHCCs }^{a} \\
(N=1260), n(\%)\end{array}$ & $p$-value ${ }^{b}$ \\
\hline Center has multiple sites ${ }^{c}$ & $190(28)$ & $N / A$ & \\
\hline Center has on-site kitchen facility ${ }^{c}$ & $610(89)$ & N/A & \\
\hline \multicolumn{4}{|l|}{ Program length } \\
\hline Both full-day and half-day & $427(62)$ & $662(53)$ & \multirow[t]{3}{*}{$<0.001$} \\
\hline Full-day & $242(35)$ & $579(46)$ & \\
\hline Half-day & $21(3)$ & $17(1)$ & \\
\hline \multicolumn{4}{|l|}{ Profit status ${ }^{c}$} \\
\hline For profit & $343(50)$ & N/A & \\
\hline Nonprofit & $306(44)$ & N/A & \\
\hline $\begin{array}{l}\text { Government (tribal, military sponsored, head start, } \\
\text { and community college) }\end{array}$ & $33(5)$ & N/A & \\
\hline College or university affiliated & $8(1)$ & N/A & \\
\hline Enrolled in early achievers ${ }^{d}$ & $425(63)$ & $438(38)$ & $<0.001$ \\
\hline \multicolumn{4}{|l|}{ CACFPe } \\
\hline Currently enrolled & $378(56)$ & $820(67)$ & $<0.001$ \\
\hline \multicolumn{4}{|l|}{ DSHS child care subsidy program } \\
\hline Has one or more families using a DSHS subsidy & $521(76)$ & $743(59)$ & \multirow[t]{3}{*}{$<0.001$} \\
\hline Does not accept DSHS subsidies & $120(18)$ & $201(16)$ & \\
\hline $\begin{array}{l}\text { Accepts DSHS subsidies, but has no families } \\
\text { who use subsidies enrolled in child care }\end{array}$ & $44(6)$ & $308(25)$ & \\
\hline
\end{tabular}

Only includes programs that reported to care for children of ages 2-5 years.

${ }^{a}$ Column totals do not sum up because missing data (unreadable, no response, and "I don't know" responses) were excluded.

${ }^{b}$ Comparisons of study groups made with Pearson's chi-squared test $\left(\chi^{2}\right)$. $p$ Values $<0.05$ were considered significant.

'These questions were only applicable to Centers.

'Washington's Quality Rating and Improvement System for early care and education facilities.

eIncluded respondents who had participated in CACFP in the past but not currently participating and those who had never participated in CACFP.

CACFP, Child and Adult Care Food Program; DSHS, Department of Social and Health Services.

\section{Table 3. Main Mode of Shopping for Washington Child Care Programs by Child Care Type}

\begin{tabular}{|c|c|c|c|c|c|c|c|c|c|}
\hline \multirow[b]{2}{*}{$\begin{array}{l}\text { Main mode } \\
\text { of shopping }\end{array}$} & \multicolumn{3}{|c|}{ Full sample $^{\mathrm{b}}(N=1950)$} & \multicolumn{3}{|c|}{ Centers $^{\mathrm{b}}(\mathrm{N}=690)$} & \multicolumn{3}{|c|}{$\operatorname{FHCCs}^{\mathrm{b}}(N=1260)$} \\
\hline & $\begin{array}{c}\text { CACFP, } \\
n(\%)\end{array}$ & $\begin{array}{c}\text { non-CACFP, } \\
n(\%)\end{array}$ & $p^{c}$ & $\begin{array}{c}\text { CACFP, } \\
n(\%)\end{array}$ & $\begin{array}{c}\text { non-CACFP, } \\
n(\%)\end{array}$ & $p^{c}$ & $\begin{array}{c}\text { CACFP, } \\
n(\%)\end{array}$ & $\begin{array}{c}\text { non-CACFP, } \\
n(\%)\end{array}$ & $p^{c}$ \\
\hline In-person & 1017 (91) & $539(92)$ & \multirow{3}{*}{0.358} & $233(7 I)$ & $170(80)$ & \multirow{3}{*}{0.038} & $784(100)$ & $369(100)$ & \multirow{3}{*}{0.96} \\
\hline Online & $78(7)$ & $39(7)$ & & $76(23)$ & $38(18)$ & & $2(0.3)$ & I $(0.3)$ & \\
\hline Phone & $19(2)$ & $5(I)$ & & $19(6)$ & $5(2)$ & & $0(0)$ & $0(0)$ & \\
\hline
\end{tabular}

${ }^{a}$ Only includes Centers and FHCCs that serve or cater at least one meal or snack to children of ages 2-5 years.

bColumn totals do not sum up because missing data (unreadable, no response, "I don't know," and "not applicable" responses) were excluded.

'Comparisons of study groups made with Pearson's chi-squared test $\left(\chi^{2}\right)$. $p$ Values $<0.05$ were considered significant. 


\begin{tabular}{|c|c|c|c|c|c|c|c|c|c|}
\hline \multirow[b]{2}{*}{ Main store for shopping } & \multicolumn{3}{|c|}{ Full sample $^{a}(N=1950)$} & \multicolumn{3}{|c|}{ Centers $^{a}(N=690)$} & \multicolumn{3}{|c|}{$\operatorname{FHCCs}^{\mathrm{a}}(N=1260)$} \\
\hline & $\begin{array}{c}\text { CACFP, } \\
n(\%)\end{array}$ & $\begin{array}{c}\text { non-CACFP, } \\
n(\%)\end{array}$ & $p^{b}$ & $\begin{array}{c}\text { CACFP, } \\
n(\%)\end{array}$ & $\begin{array}{c}\text { non-CACFP } \\
n(\%)\end{array}$ & $p^{b}$ & $\begin{array}{c}\text { CACFP, } \\
n(\%)\end{array}$ & $\begin{array}{c}\text { non-CACFP, } \\
n(\%)\end{array}$ & $p^{b}$ \\
\hline Megastores $^{\mathrm{c}}$ & $367(32)$ & $225(35)$ & \multirow{6}{*}{0.001} & $147(4 \mid)$ & $137(53)$ & \multirow{6}{*}{$<0.001$} & $25 I(3 I)$ & $153(40)$ & \multirow{6}{*}{0.034} \\
\hline No main store & $289(25)$ & $185(29)$ & & $38(11)$ & $32(12)$ & & $220(27)$ & $88(23)$ & \\
\hline Food service distributors ${ }^{d}$ & $109(9)$ & $28(4)$ & & $109(3 \mathrm{I})$ & $28(11)$ & & $0(0)$ & $0(0)$ & \\
\hline Other & $16(I)$ & $7(1)$ & & $0(0)$ & $2(1)$ & & $16(2)$ & $5(1)$ & \\
\hline Grocery stores ${ }^{f}$ & $321(28)$ & $172(27)$ & & $48(14)$ & $53(2 I)$ & & $273(34)$ & $119(31)$ & \\
\hline Two stores and more & $55(5)$ & $20(3)$ & & $13(4)$ & $6(2)$ & & $42(5)$ & $14(4)$ & \\
\hline
\end{tabular}

Only includes Centers and FHCCs that serve or cater at least one meal or snack to children of ages 2-5 years.

${ }^{a}$ Column totals do not sum up to total because missing data (unreadable, no response, and "I don't know" responses) were excluded.

${ }^{b}$ Comparisons of study groups made with Pearson's chi-squared test $\left(\chi^{2}\right)$. $p$ Values $<0.05$ were considered significant.

'Megastores indicate Costco, Target, Walmart, and Sam's Club.

'Food service distributors indicate Sysco, FSA, FSI, US Foods, URM, Amazon Fresh, UNFI, Charlie's Produce, and NW Deli.

eOther indicate organic, commissary, vendors, and farmers markets.

${ }^{f}$ Grocery stores indicate Albertsons, QFC, Safeway, Trader Joes, WinCo, co-ops, etc.

\section{Discussion}

To our knowledge, this study is the first to look at child care food procurement practices and the relationship between procurement practices and the nutritional quality of foods served to children in ECE settings. We found that the majority of Centers and FHCCs prefer in-person shopping over phone or online shopping and that most ECE programs shop primarily at megastores followed by grocery stores.
Using bivariate analyses, we found that provider sociodemographics (i.e., race/ethnicity, education, and years of ECE employment) and CACFP participation are associated with the nutritional quality of foods in child care programs. Using multinomial analyses adjusted for select covariates, all three models found a significant association between shopping at two or more stores and higher nutritional quality of foods offered in child care programs in this sample and between online shopping and higher

\begin{tabular}{|c|c|c|c|c|c|c|c|c|c|}
\hline \multirow[b]{3}{*}{ Content area } & \multicolumn{2}{|c|}{ Full sample $^{a}(N=1950)$} & \multirow[b]{3}{*}{$p^{b}$} & \multicolumn{2}{|c|}{ Centers $^{\mathrm{a}}(\mathrm{N}=690)$} & \multirow[b]{3}{*}{$p^{b}$} & \multicolumn{2}{|c|}{$\operatorname{FHCCs}^{a}(N=1260)$} & \multirow[b]{3}{*}{$p^{b}$} \\
\hline & $\begin{array}{c}\text { CACFP } \\
(n=1198)\end{array}$ & $\begin{array}{c}\text { non-CACFP } \\
(n=704)\end{array}$ & & $\begin{array}{c}\text { CACFP } \\
(n=378)\end{array}$ & $\begin{array}{c}\text { non-CACFP } \\
(n=301)\end{array}$ & & $\begin{array}{l}\text { CACFP } \\
(n=820)\end{array}$ & $\begin{array}{c}\text { non-CACFP } \\
(n=403)\end{array}$ & \\
\hline & \multicolumn{2}{|c|}{ Mean \pm SD } & & \multicolumn{2}{|c|}{ Mean \pm SD } & & \multicolumn{2}{|c|}{ Mean \pm SD } & \\
\hline Fruits and vegetables & $3.67 \pm 0.7$ & $3.66 \pm 0.8$ & 0.810 & $3.37 \pm 0.69$ & $3.4 \pm 0.8$ & 0.543 & $3.81 \pm 0.66$ & $3.85 \pm 0.75$ & 0.306 \\
\hline Snack foods and sweets & $3.66 \pm 0.43$ & $3.63 \pm 0.51$ & 0.123 & $3.79 \pm 0.40$ & $3.66 \pm 0.47$ & $<0.001$ & $3.6 \pm 0.44$ & $3.6 \pm 0.53$ & 0.949 \\
\hline $\begin{array}{l}\text { Fried foods and } \\
\text { processed meat }\end{array}$ & $3.7 \pm 0.68$ & $4.07 \pm 0.81$ & $<0.001$ & $3.93 \pm 0.65$ & $4.39 \pm 0.7$ & $<0.001$ & $3.6 \pm 0.67$ & $3.84 \pm 0.82$ & $<0.001$ \\
\hline Beverages & $4.38 \pm 0.55$ & $3.83 \pm 0.67$ & $<0.001$ & $4.51 \pm 0.47$ & $4.01 \pm 0.59$ & $<0.001$ & $4.32 \pm 0.57$ & $3.7 \pm 0.69$ & $<0.001$ \\
\hline Supporting healthy eating & $4.01 \pm 0.63$ & $3.94 \pm 0.62$ & 0.028 & $4.43 \pm 0.53$ & $4.22 \pm 0.54$ & $<0.001$ & $3.82 \pm 0.58$ & $3.74 \pm 0.6 \mathrm{I}$ & 0.042 \\
\hline Composite score & $3.90 \pm 0.36$ & $3.8 I \pm 0.4 I$ & $<0.001$ & $4.01 \pm 0.33$ & $3.9 \pm 0.39$ & $<0.001$ & $3.85 \pm 0.35$ & $3.74 \pm 0.42$ & $<0.001$ \\
\hline
\end{tabular}

Only includes Centers and FHCCs that serve or cater at least one meal or snack to children of ages 2-5 years.

aTable excludes respondents who did not respond to CACFP participation. Two percent $(n=42)$ FHCCs and Centers responded "I don't know" and $0.3 \%(n=6)$ FHCCs and Centers had unreadable responses to CACFP participation.

${ }^{b}$ Comparison of study groups done using independent sample $t$-test and analysis of variance. $p$ Values $<0.05$ were considered significant. 


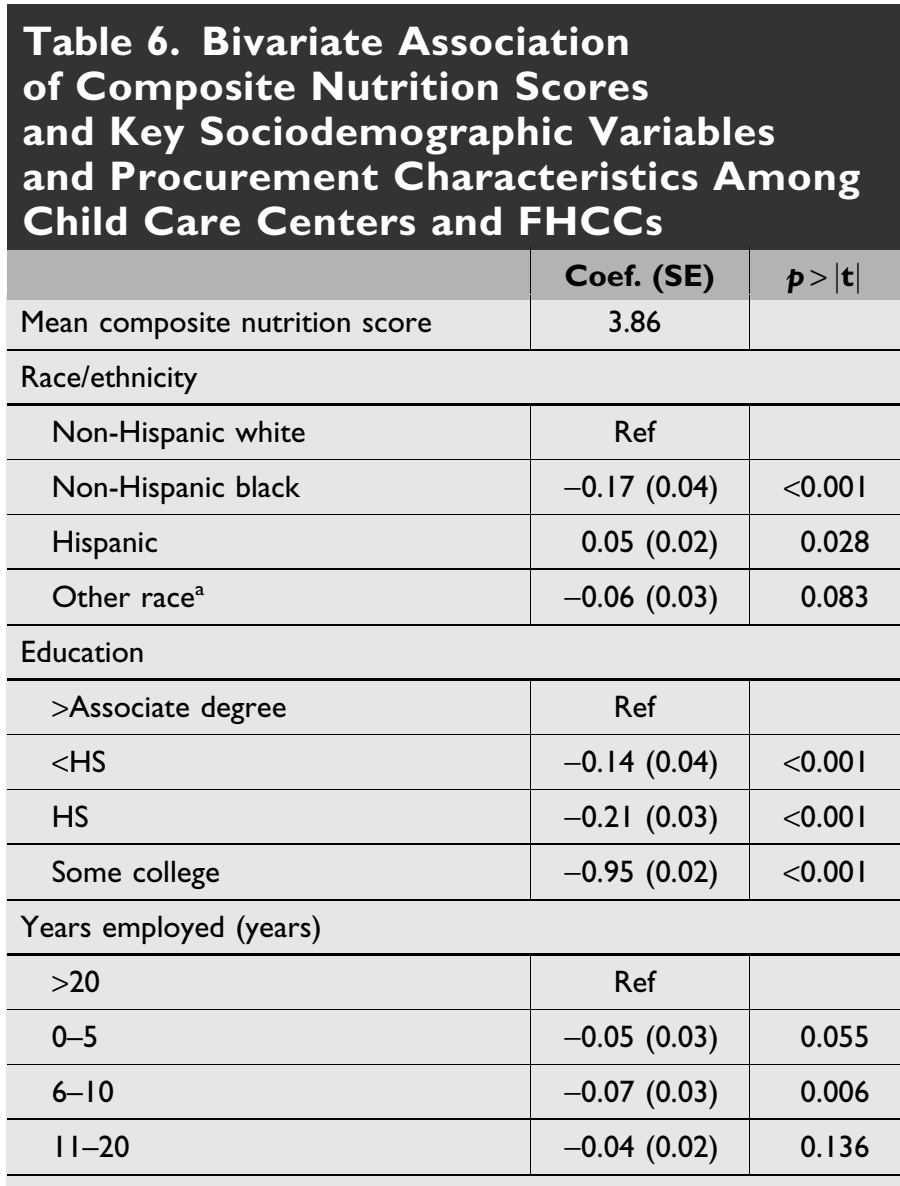

\begin{tabular}{|c|c|c|}
\hline \multicolumn{3}{|l|}{ Main store for shopping } \\
\hline Megastores ${ }^{b}$ & Ref & \\
\hline No main store & $-0.05(0.02)$ & 0.048 \\
\hline Food service distributors ${ }^{c}$ & $0.18(0.04)$ & $<0.001$ \\
\hline Other stores $^{d}$ & $0.04(0.08)$ & 0.591 \\
\hline Grocery stores ${ }^{e}$ & $-0.06(0.02)$ & 0.007 \\
\hline$>2$ stores & $0.14(0.05)$ & 0.001 \\
\hline
\end{tabular}

\begin{tabular}{|c|c|c|}
\hline \multicolumn{3}{|c|}{ Main shopping mode } \\
\hline In-person & Ref & \\
\hline Online & $0.26(0.04)$ & $<0.001$ \\
\hline Phone & $0.11(0.08)$ & 0.17 \\
\hline \multicolumn{3}{|c|}{ Type of child care } \\
\hline FHCC & Ref & \\
\hline Center & $0.15(0.02)$ & $<0.001$ \\
\hline
\end{tabular}

\begin{tabular}{l|c|c}
\hline \multicolumn{1}{|c|}{ Enrolled } & Ref & \\
\hline Not enrolled & $-0.09(0.02)$ & $<0.001$ \\
\hline Early achievers & Ref & \\
\hline Not enrolled & $0.11(0.02)$ & $<0.001$ \\
\hline Enrolled & \multicolumn{3}{|c}{ continued on page 435 }
\end{tabular}

Table 6. Bivariate Association

of Composite Nutrition Scores

and Key Sociodemographic Variables

and Procurement Characteristics Among

Child Care Centers and FHCCs continued

\begin{tabular}{|c|c|c|}
\hline & Coef. (SE) & $\mathbf{p}>|\mathbf{t}|$ \\
\hline \multicolumn{3}{|l|}{ DSHS subsidy } \\
\hline $\begin{array}{l}\text { More than one family } \\
\text { using subsidy }\end{array}$ & Ref & \\
\hline Does not accept subsidy & $0.08(0.02)$ & $<0.001$ \\
\hline $\begin{array}{l}\text { Accepts subsidy, but no families } \\
\text { currently enrolled }\end{array}$ & $-0.03(0.02)$ & 0.249 \\
\hline
\end{tabular}

${ }^{\text {a } O t h e r ~ r a c e ~ i n c l u d e s ~ A s i a n s, ~ P a c i f i c ~ I s l a n d e r s, ~ A m e r i c a n ~ I n d i a n s, ~}$ unique races, and mixed races.

bMegastores indicate Costco, Target, Walmart, and Sam's Club.

'Food service distributors indicate Sysco, FSA, FSI, US Foods, URM, Amazon Fresh, UNFI, etc.

${ }^{d}$ Other stores indicate organic, commissary, vendors, and farmers markets.

'Grocery stores indicate Albertsons, QFC, Safeway, Trader Joes, WinCo, co-ops, etc.

SE, standard error.

nutritional quality as compared with shopping at megastores or shopping in-person, respectively.

These findings are important because they illustrate that the majority of ECE programs purchase food in-person at megastores and grocery stores rather than through phone or online or using other venue types, such as food service distributors. At the same time, shopping online or at two or more stores was associated with higher nutrition scores. Thus, policies and programs that are being designed to reach ECE sites with messages or behavioral interventions targeted at healthy food purchasing patterns may want to explore the reasons why shopping at two or more stores or online might be associated with healthier food purchasing patterns, and, if considering the greatest reach, consider inperson interventions with retailers at megastores and grocery stores.

Our finding that the vast majority of programs prefer in-person shopping is consistent with a 2015 National Bureau of Economic Research (NBER) working article, which found that the proliferation of online retailers in the marketplace had not decreased the traditional in-person shopping mode for food and beverages. ${ }^{38}$ The study authors concluded that physical in-person shopping for food and beverages is likely to stay the norm for the next couple of years, if not decades. ${ }^{38} \mathrm{~A}$ small qualitative study on the food purchasing habits of ECE programs found that most programs were doubtful of purchasing food online. ${ }^{11,26} \mathrm{ECE}$ 
Table 7. Odds Ratios from Multinomial Logistic Regression Models Predicting Likelihood
of Composite Nutrition Score Category as a Function of Procurement Characteristics
(Main Store for Shopping and Main Shopping Mode) after Adjusting for Select Covariates

\begin{tabular}{|c|c|c|c|c|c|c|c|c|c|}
\hline \multirow[b]{3}{*}{ Procurement characteristics } & \multicolumn{3}{|c|}{ Model I $(n=1662)$} & \multicolumn{3}{|c|}{ Model $2(n=1662)$} & \multicolumn{3}{|c|}{ Model $3(n=1625)$} \\
\hline & \multicolumn{9}{|c|}{ High composite nutrition score category vs. low composite nutrition score } \\
\hline & Odds ratio & $95 \% \mathrm{Cl}$ & $\mathbf{p}$ & Odds ratio & $95 \% \mathrm{Cl}$ & $p$ & Odds ratio & $95 \% \mathrm{Cl}$ & $\mathbf{p}$ \\
\hline \multicolumn{10}{|l|}{ Main store for shopping } \\
\hline Megastores $^{\mathrm{a}}$ & \multicolumn{3}{|c|}{ Ref } & \multicolumn{3}{|c|}{ Ref } & \multicolumn{3}{|c|}{ Ref } \\
\hline No main store & 0.88 & $0.64-1.22$ & 0.446 & 1.00 & $0.7 I-1.40$ & 0.989 & 0.89 & $0.64-1.23$ & 0.469 \\
\hline Food service distributors ${ }^{b}$ & 2.78 & $1.17-6.57$ & 0.020 & 2.40 & $1.00-5.74$ & 0.049 & 2.35 & $0.98-5.63$ & 0.056 \\
\hline Other $^{c}$ & 1.76 & $0.56-5.55$ & 0.333 & 2.06 & $0.65-6.52$ & 0.221 & 1.64 & $0.52-5.19$ & 0.400 \\
\hline Grocery stores $^{d}$ & 0.85 & $0.62-1.17$ & 0.324 & 0.95 & $0.69-1.31$ & 0.756 & 0.86 & $0.62-1.18$ & 0.344 \\
\hline More than two stores & 2.25 & $1.16-4.36$ & 0.016 & 2.44 & $1.26-4.75$ & 0.009 & 2.22 & $\mathrm{I} .12-4.4 \mathrm{I}$ & 0.022 \\
\hline \multicolumn{10}{|l|}{ Main shopping mode } \\
\hline In person & \multicolumn{3}{|c|}{ Ref } & \multicolumn{3}{|c|}{ Ref } & \multicolumn{3}{|c|}{ Ref } \\
\hline Online & 3.16 & $1.43-7.01$ & 0.005 & 2.65 & $1.18-5.96$ & 0.018 & 3.42 & I.53-7.65 & 0.003 \\
\hline Phone & 0.66 & $0.18-2.38$ & 0.524 & 0.58 & $0.16-2.11$ & 0.412 & 0.70 & $0.19-2.55$ & 0.591 \\
\hline
\end{tabular}

aMegastores indicate Costco, Target, Walmart, and Sam's Club.

${ }^{b}$ Food service distributors indicate Sysco, FSA, FSI, US Foods, URM, Amazon Fresh, UNFI, etc.

'Other stores indicate organic, commissary, vendors, farmers markets.

${ }^{\mathrm{d} G r o c e r y}$ stores indicate Albertsons, QFC, Safeway, Trader Joes, WinCo, co-ops, etc.

eAll models compared the high composite nutrition score category with the low nutrition score category (base). Model I: Adjusted for race/ ethnicity, education, and years employed. Model 2: Adjusted for race/ethnicity, education, years employed, and type of child care. Model 3:

Adjusted for race/ethnicity, education, years employed, type of child care, and CACFP enrollment.

$\mathrm{Cl}$, confidence interval.

interviewees explained the challenges of online ordering: they did not trust the food quality of products, they found that determining whether products or product substitutions met food standards or legal requirements was difficult, and they often found that the minimum requirements for online purchasing and delivery were prohibitive, especially in the face of limited on-site storage space. ${ }^{26}$

Our finding that ECE programs use megastores most, followed by grocery stores, regardless of CACFP participation, is not surprising. Megastores are typically larger and carry a wider variety of food and nonfood products than supermarkets or grocery stores. ${ }^{39,40}$ Prices at megastores also average $7 \%$ lower than grocery stores. ${ }^{39}$ Grocery stores were also frequently used by respondents and this may be because they offer more than three times the assortment within product categories than megastores or because many ECE sites throughout Washington State are not located in proximity to a megastore. ${ }^{39,41}$ In this study, we found that food service distributors were less commonly used. One challenge with procuring food through food service distributors is the issue of minimum orders, which can range from $\$ 100$ per order for small distributors to $\$ 750$ per order for large distributors. ${ }^{42}$ A food service distributor model for ECE settings may work if ECE sites serve at least 20 meals/day, excluding snacks, in addition to having storage space. ${ }^{42}$

The bivariate associations presented in these analyses found that staff members who have worked in ECE settings longer and have higher levels of education were associated with higher nutrition scores. Our sample of FHCC providers had lower education levels than Center providers, and this may be because the Washington Administrative Code (WAC) requires different levels of education for Center directors and FHCC providers. Although Center directors are required to have at least some college-level education in the area of early childhood and development, FHCC providers must have at minimum a HS diploma or equivalent education. ${ }^{43,44}$ Although research generally supports that well-educated professionals promote highquality ECE settings, the relationship between education and nutrition quality is complex, and prior studies have been inconsistent with how education is gauged. ${ }^{45,46} \mathrm{In}$ addition, this relationship is not necessarily linear due to potential confounders and mediators such as race, 
class, gender, age, educational opportunity, and workplace experiences. ${ }^{45,46}$

Similar to many other studies, this study found that CACFP enrollment was positively associated with the quality of nutrition in child care. ${ }^{12-14}$ In this study, CACFP sites had higher nutrition scores for beverages and for environments that support healthy eating, both for Centers and for FHCCs. Nationally, CACFP serves 3.3 million children every day, and participating sites must comply with specific meal patterns to be eligible. ${ }^{47}$ Prior literature shows that CACFP participation is positively associated with the consumption of milk and vegetables, as well as lower BMI, particularly among low-income children. ${ }^{12} \mathrm{We}$ found that CACFP enrollment was $<70 \%$, both for Centers and FHCCs, indicating that there may be room for including more sites in the program.

Because CACFP has been so positively related to nutrition in ECE settings, one way to improve nutrition at the point of food purchase might be through the use of labels or signage that indicate foods and beverages meet CACFP standards at locations where and how child care caregivers shop the most, such as in-person at megastores and grocery stores. Customers desire support (i.e., shelf labels identifying healthy products, in-store product sampling or tasting, healthy meal ideas and recipes, etc.) in purchasing healthy products, and front of package and simple shelflabeling systems have been shown to be beneficial in supporting healthy food purchases. ${ }^{48,49}$ However, there are currently no labels at the point-of-purchase that are child care-specific to nutrition.

One label that exists for child nutrition $(\mathrm{CN})$ programs, in general, is the $\mathrm{CN}$ labeling, which is run by the federal USDA Food and Nutrition Service in collaboration with commercial food processing firms. ${ }^{50}$ This label only identifies the quantifiable contribution of a product toward meal pattern requirements, using yields from USDA's Food Buying Guide for Child Nutrition Programs, and does not indicate nutritional value. ${ }^{50,51}$ Moreover, ECE programs are not federally mandated to purchase $\mathrm{CN}$ foods. Instead, purchasing decisions are locally determined. ${ }^{50}$ There may be an opportunity here for public agencies to collaborate with megastores and grocery stores to develop child care-specific nutrition labels for foods that meet best practice standards to ease purchasing decisions.

Finally, our findings suggest that food procurement characteristics may be related to the nutritional quality of foods offered to children in ECE. Future studies should explore whether these relationships are consistent across other ECE samples and why online shopping or shopping at two or more main stores was associated with higher nutritional quality. This study has several limitations. A major limitation is that our analysis is a secondary analysis of existing survey data. Although the original survey aimed to better understand the nutrition, physical activity and screen time practices, and environments of WA's licensed ECE settings, we were more interested in understanding the relationship between procurement practices and nutrition in
ECE settings. Although our specific aim was not the primary focus in the original survey, the advisory group for the original survey did suggest using the collected data to examine the association between food practices and shopping locations and was intentional about including procurement-type questions for this type of secondary analysis. Future research with these relationships as primary aim may be able to add more and more robust questions on food procurement, such as how nutritionrelated cues are used at the point-of-selection, and/or obtain actual receipt or purchase data by stores for more granularity. Second, the cross-sectional study design limits our ability to understand these relationships over time. Third, the survey had a $36 \%$ response rate. Other survey studies report $35 \%-45 \%$ response rates, suggesting that this response rate is within the common range. ${ }^{52-55}$ However, there may be selection or response bias associated with those who responded since respondents who choose to answer surveys may differ from those who do not and because respondents might have wanted to portray their child care programs positively. Although survey respondents were guaranteed confidentiality, fear of consequences related to their child care licenses may have also resulted in response bias. Fourth, we were unable to incorporate food cost into the analyses and this variable may have altered our findings. Although respondents were asked to indicate how much money the program spent on food, most responses were implausible. This could have been due to poor wording and/or understanding of the question. Future surveys should pretest cost questions to obtain information about food costs accurately. Fifth, given the multiple analyses done on this data set, there is possibility of multiple inferences, wherein some of the statistically significant findings may have occurred by chance. In addition, given the design of the total nutrition score, the practical significance of some of the statistically significant findings in our analyses with regard to informing practices or policies is unknown. Finally, our ability to generalize the results of this survey to other states may be limited since ECE regulations and licensing vary from state to state. Despite these limitations, this exploratory secondary analysis is informative because it illustrates where and how a majority of child care providers and caregivers procure their foods, possibly informing the design of interventions that might be aimed at supporting healthy ECE food purchases.

\section{Conclusion}

By identifying the food procurement practices (i.e., how and where programs shop) of ECE programs, we illuminate potential points of policy or program intervention to support healthy food purchases. We found that ECE programs primarily shop at megastores followed by grocery stores and prefer in-person shopping, although some ECE Centers indicated a preference for online shopping. ECE food procurement practices were related to the nutritional 
quality of foods served by ECE programs with shopping at two or more stores or online shopping being consistently associated with higher nutrition scores than shopping at megastores or in-person.

Since policy and program interventions often have limited funding and are often targeted at reaching the greatest number possible, this study suggests that interventions to increase healthy food purchases may be best delivered using in-person strategies, such as using ECEspecific labeling systems at megastores and grocery stores, followed by online interventions. Future studies should also explore the reasons why shopping online or at two or more stores was associated with higher nutrition scores.

\section{Acknowledgment}

Financial support and grants: Original data were collected with a grant support from the Washington State Department of Health and Public Health-Seattle \& King County.

\section{References}

1. Benjamin Neelon SE, Briley ME. Position of the American Dietetic Association: Benchmarks for Nutrition in Child Care. J Am Diet Assoc 2011;111:607-615.

2. Birch LL. Development of food preferences. Annu Rev Nutr 1999; 19:41-62.

3. Mura Paroche M, Caton SJ, Vereijken CMJL, et al. How infants and young children learn about food: A systematic review. Front Psychol 2017;8. DOI:10.3389/fpsyg.2017.01046

4. Benjamin SE, Rifas-Shiman SL, Taveras EM, et al. Early child care and adiposity at ages 1 and 3 years. Pediatrics 2009;124: $555-562$.

5. Lumeng JC, Gannon K, Appugliese D, et al. Preschool child care and risk of overweight in 6- to 12-year-old children. Int $J$ Obes 2005;29:60-66.

6. Black MM, Walker SP, Fernald LCH, et al. Early childhood development coming of age: Science through the life course. Lancet 2017;389:77-90.

7. Herman DR, Taylor Baer M, Adams E, et al. Life course perspective: Evidence for the role of nutrition. Matern Child Health $J$ 2014;18:450-461.

8. Peisner-Feinberg ES. Child care and its impact on young children. Encyclopedia on Early Childhood Development [online]. 2011; (November 2003):1-7.

9. Lynch M, Batal M. factors influencing childcare providers' food and mealtime decisions: An ecological approach. Child Care Pract 2011;17:185-203.

10. Henderson KE, Grode GM, Middleton AE, et al. Validity of a measure to assess the child care nutrition and physical activity environment. J Am Diet Assoc 2014;111:1306-1313.

11. Otten JJ, Hirsch T, Lim C. Factors influencing the food purchases of early care and education providers. J Acad Nutr Diet 2017;117: $725-734$.

12. Korenman S, Abner KS, Kaestner R, Gordon RA. The child and adult care food program and the nutrition of preschoolers. Early Child Res Quart 2013;28:1-27.
13. Liu ST, Graffagino CL, Leser KA, et al. Obesity prevention practices and policies in child care settings enrolled and not enrolled in the child and adult care food program. Matern Child Health $J$ 2016;20:1933-1939.

14. Monsivais P, Kirkpatrick S, Johnson DB. More nutritious food is served in child-care homes receiving higher federal food subsidies. $J$ Am Diet Assoc 2011;111:721-726.

15. Sigman-grant M, Christiansen E, Fernandez G, et al. Child care provider training and a supportive feeding environment in child care settings in 4 states, 2003. Prev Chronic Dis 2011;8:A113.

16. The National Academies of Sciences. Review of Child and Adult Care Food Program Meal Requirements: Detailed Information. National Academies Press, Washington, DC, 2010.

17. Robles B, Wood M, Kimmons J, Kuo T. Comparison of nutrition standards and other recommended procurement practices for improving institutional food offerings in Los. Adv Nutr 2013;4: 191-202.

18. Elliot V, Carr DH, Nettles MF. Procurement Practices Influencing Programs Operating Within the Guidelines of the Child And Adult Care Food Program: A Review of Literature. University of Southern Mississippi, Hattiesburg, MS, 2005.

19. The Pew Charitable Trusts. CACFP Health Impact Assessment: Methodological Supplement. The Pew Charitable Trusts, Philadelphia, PA, 2017.

20. Gardner CD, Whitsel LP, Thorndike AN, et al. Food-and-beverage environment and procurement policies for healthier work environments. Nutr Rev 2014;72:390-410.

21. Aggarwal A, Cook AJ, Jiao J, et al. Access to supermarkets and fruit and vegetable consumption. Am J Public Health 2014;104: 917-923.

22. Morland K, Roux AVD, Wing S. Supermarkets, other food stores, and obesity: The atherosclerosis risk in Communities Study. Am J Prev Med 2006;30:333-339.

23. Kalnikaite V, Bird J, Rogers Y. Decision-making in the aisles: Informing, overwhelming or nudging supermarket shoppers? Pers Ubiquit Comput 2013;17:1247-1259.

24. Gao F, Costanza E, Schraefel MC. "Honey=Sugar" means unhealthy: Investigating how people apply knowledge to rate food's healthiness. Proceedings of the 2012 ACM Conference on Ubiquitous Computing. Southampton. Association for Computing Machinery (ACM): Hampshire, United Kingdom, 2012, pp. 71-80.

25. Aggarwal A, Rehm CD, Monsivais P, Drewnowski A. Importance of taste, nutrition, cost and convenience in relation to diet quality: Evidence of nutrition resilience among US adults using National Health and Nutrition Examination Survey (NHANES) 2007-2010. Prev Med 2016;90:184-192.

26. Hirsch T, Lim C, Otten JJ. What's for lunch? A socio-ecological approach to childcare nutrition. Proceedings of the 2016 ACM Conference on Designing Interactive Systems. Association for Computing Machinery (ACM): Brisbane, Australia, 2016, pp. $1160-1171$.

27. Tandon PS, Walters KM, Igoe BM, et al. Physical activity practices, policies and environments in Washington state child care settings: Results of a statewide survey. Matern Child Health $J$ 2017;21:571-582.

28. University of Washington Center for Public Health Nutrition (CPHN). The 2013 Washington State Survey of Nutrition and Physical Activity in Child Care. University of Washington Center for Public Health Nutrition, Seattle, WA, 2013.

29. American Academcy of Pediatrics, American Public Health Association NRC for Health and Safety in Child Care and Early Education. Caring for Our Children: National Health and Safety Performance Standards; Guidelines for Early Care and Education 
Programs, 3rd ed., American Academy of Pediatrics, Washington, DC, 2011.

30. Boyle M, Celano G, Cooper E, et al. Best Practices for Healthy Eating. The Nemours Foundation, Wilmington, DE, 2013.

31. The Nemours Foundation. Let's Move! Child Care. The Neumours Foundation. 2017. Available at https://healthykidshealthyfuture .org Last accessed March 11, 2017.

32. Hughes D, Phillips KD, Boyle M, et al. Best Practices for Physical Activity: A Guide To Help Children Grow Up Healthy. The Nemours Foundation, Wilmington, DE, 2013. DOI:10.1249/ MSS.0b013e3182399e5b.BEST

33. Atkins Center for Weight and Health, University of California, Berkeley, California Food Policy Advocates, and Samuels \& Associates. Survey of Child Care Providers of 2-5 Year Old Children. The Robert Wood Johnson Foundation, Berkeley, CA, 2011.

34. Bellanca HK. Right from the Start: Assessing Child Care Settings in Multnomah County for Obesity Prevention. Portland, 2011.

35. Ward D, Morris E, McWilliams C, et al. Go NAP SACC: Nutrition and Physical Activity Self-Assessment for Child Care, 2nd ed. The University of North Carolina at Chapel Hill, Chapel Hill, NC, 2014.

36. Yale Rudd Center. Child Care Nutrition and Physical Activity Assessment Survey. Yale University, New Haven, CT, 2007.

37. Hoddinott SN, Bass MJ. The Diliman total design survey method: A sure-fire way to get high survey return rates. Can Fam Phys 1986;32:2366-2368.

38. Hortaçsu A, Syverson C. The ongoing evolution of US retail: A format tug-of-war. J Econ Persp 2015;29:89-112.

39. Taillie LS, Ng SW, Popkin BM. Global growth of "big box" stores and the potential impact on human health and nutrition. Nutr Rev 2016;74:83-97.

40. Demmler KM, Ecker O, Qaim M. Supermarket Shopping and Nutritition Outcomes: A Panel Data Analysis for Urban Kenya. Göttingen, Germany, 2017. Report No. Paper 91.

41. Fox EJ, Montgomery AL, Lodish LM, et al. Consumer shopping and spending across retail formats. $J$ Business 2004;77:S25-S60.

42. Mauden K. Farm to Table Partnership: Assessing Delivery Models for Childcare and Senior Meal Programs, Public Health Seattle, King County, Seattle, WA, 2012.

43. Washington State Legislature. Title 170: Chapter 170-295 WAC Minimum Licensing Requirements for Child Care Centers. Washington State Legislature: Olympia, 2017.

44. Washington State Legislature. Title 170: Chapter 170-296A WAC Licenced Family Home Child Care Standards. Washington State Legislature: Olympia, 2017.

45. Zimmerman EB, Woolf SH, Haley A. Population health: Behavioral and social science insights - Understanding the relationship between education and health. Agency for Healthcare Research and Quality. 2015. Available at https://www.ahrq.gov/professionals/education/ curriculum-tools/population-health/zimmerman.html Last accessed December 5, 2017.

46. Cohen AK, Rai M, Rehnkopf DH, Abrams B. Educational attainment and obesity: A systematic review. Obes Rev 2014;14:989-1005.

47. United States Department of Agriculture (USDA) Food and Nutrition Service (FNS). Child and Adult Care Food Program (CACFP). 2014. Available at https://www.fns.usda.gov/cacfp/why-cacfp-important Last accessed January 1, 2017.

48. Gordon E, Dawkins-Lyn N, Hogan-Yarbro R, et al. Approaches for Promoting Healthy Food Purchases by SNAP Participants. US Department of Agriculture, Food and Nutrition Service, Office of Policy Support, Calverton, MD, 2014.

49. The Food Trust, Robert Wood Johnson Foundation. Harnessing the Power of Supermarkets to Help Reverse Childhood Obesity. Robert Wood Johnson Foundation, Princeton, NJ, 2011.

50. United States Department of Agriculture (USDA), Food and Nutrition Service. CN labeling. 2017. Available at https://www.fns.usda.gov/ cnlabeling/child-nutrition-cn-labeling-program Last accessed January $1,2017$.

51. United States Department of Agriculture (USDA), Food and Nutrition Service (FNS). Food buying guide for child nutrition programs. 2017. Available at https://www.fns.usda.gov/tn/food-buying-guidefor-child-nutrition-programs Last accessed January 1, 2017.

52. Sigman-Grant M, Christiansen E, Branen L, et al. About feeding children: Mealtimes in child-care centers in four Western States. $J$ Am Diet Assoc 2008;108:340-346.

53. Hecht K, Samuels S, Crawford P. Nutrition and physical activity environments in licensed child care: A statewide assessment of California. 2009. Available at https://cfpa.net/ChildNutrition/Child Care/CFPAPublications/RWJF-StatewideChildCareAssessment-2009 .pdf Last accessed September 1, 2018.

54. Ritchie LD, Boyle M, Chandran K, et al. Participation in the child and adult care food program is associated with more nutritious foods and beverages in child care. Childhood Obes 2012; $8: 224-229$.

55. Sisson SB, Campbell JE, May KB, et al. Assessment of food, nutrition, and physical activity practices in oklahoma child-care centers. J Acad Nutr Diet 2012;112:1230-1240.

Address correspondence to: Jennifer J. Otten, PhD, RD University of Washington, School of Public Health Nutritional Sciences Program Center for Public Health Nutrition Box 353410 Seattle, WA, 98195

E-mail: jotten@uw.edu 